\section{Indloor and Buinlt \\ Environment}

\title{
Thermal Analysis of the Domed Vernacular Houses of Harran, Turkey
}

\author{
Tahsin Başaran \\ Department of Mechanical Engineering, Dokuz Eylül University, Bornova, İzmir, Turkey
}

\author{
Key Words \\ Harran houses - Vernacular houses - Sustainable \\ architecture - Thermal analysis · Solar chimney . \\ Climatic design
}

\begin{abstract}
Minimum energy consumption and economic efficiency using local and recyclable materials is essential for achieving sustainability, considering the depletion of global energy sources. The Anatolian Peninsula presents a diverse range of local building construction techniques accumulated over centuries, which meet the criteria mentioned above. Due to richness of climatic variety and the influence of many civilisations throughout history, Anatolian regions reflect this richness in their respective solutions to building construction. Built mainly out of brick and stone, mortared and plastered by mud, the domed vernacular houses of Harran, a small town in the province of Urfa in the hot arid climate of southeastern Anatolia, are one of the best examples that deserve attention with respect to minimum energy consumption. In this study, the thermal performance of the "Harran house" as a vernacular type was analysed. For this purpose, temperatures inside and outside a Harran house complex with relative humidity variations were measured. In addition, for investigating the domed houses' thermal behaviour,
\end{abstract}

temperature measurements at different surfaces and media were recorded. The solar chimney effect obtained from the dome and the importance of the thermal mass of the square base of the house were also evaluated. The study yielded results, which showed that the indoor conditions were within the limits for thermal comfort even under extreme summer conditions.

\section{Introduction}

The depletion of energy sources in addition to its disastrous environmental consequences makes the efficient use of energy imperative for a sustainable future. Since buildings are the most significant consumers of energy and construction materials, energy efficiency and sustainability in building design top the construction agenda. In trying to overcome global warming and the related energy crisis, buildings erected from recycled and local materials consuming minimum energy have been promoted around the world.

Anatolia, owing to its vast cultural heritage, has a significant but largely unexplored history of construction techniques and architectural typologies for energy-efficient and climate-sensitive design. With their relatively 
comfortable interior compared to extreme outside conditions, especially in summer time, the vernacular domed houses of Harran are important examples that deserve investigation. The specific architecture of the Harran house, a thick stone base that provides thermal storage with an opening at the top of the dome that facilitates natural ventilation as a solar chimney, presents an interesting case. Furthermore, the use of local and recyclable materials in these houses could also strengthen their potential for sustainable design in terms of economic, environmental, and indoor thermal comfort considerations.

The literature on the evaluation of energy-efficient design in vernacular buildings displays several different points of view by designers and scientists from different parts of the world [1-4]. For instance, Yolmaz [1] compared the thermal performance of buildings in İstanbul and Mardin according to Turkish standards, TS 825, Heating Energy Conservation Standard for Buildings in Turkey. Mardin, which lies close to the Harran region, also lies in a hot-arid climatic zone. This study revealed that TS 825 could be quite inaccurate since it does not consider the heat storage capacity of buildings. This consideration becomes more important for buildings that have great thermal mass capacity like vernacular houses in Mardin of heavy stone construction. Using software, natural ventilation possibilities, compared to a mechanical air-conditioning system in a traditional Italian building for three sites, was investigated numerically by Cardinale et al. [2]. Their investigation focused on the reduction of cooling loads for summer, based on natural ventilation according to different orientations of the building. Their results showed that significant energy saving could be possible between $16 \%$ and $53 \%$ using two different natural ventilation schemes for three different orientations at three mentioned sites. A field survey of thermal comfort obtained by Ealiwa et al. [3] was assembled from houses of local vernacular construction materials and techniques and contemporary modern construction techniques in Libya. They concluded that the occupants were more satisfied in naturally ventilated local vernacular houses than in the contemporary air-conditioned houses. Using numerical calculations by software, Harputligil and Çetintürk [4] provided the thermal analysis of a local vernacular construction type of $\mathrm{Hac} \iota$ Hüseyinler in Safranbolu in the northwestern Black Sea region of Turkey. They showed that the average annual energy consumption of the Hacı Hüseyinler house, which was built in 1870 s, could provide sufficient energy consumption suggested for Turkey by the International
Energy Agency. Like the above-mentioned examples, what makes these vernacular structures noteworthy for research is the good indoor thermal conditions that these houses could provide, which has led to the research focus on the thermal behaviour of the domed houses of Harran by the author. Both the cultural heritage value and their significant architectural features regarding energy-efficient design and recycling of materials have made the domed houses of Harran an important research case for sustainable development.

In this study, the thermal performance of a typical domed house of Harran was investigated under extreme summer conditions. In the author's opinion, since these houses are not only environment-friendly buildings built out of natural materials with "climatic designs", which provide good indoor conditions, they are also "flexible structures" which can be rapidly built by a single craftsman (in almost a day), which makes them worthy of recognition for their construction features and thermal behaviour.

\section{Materials and Methods}

As an important ancient city of southeast Anatolia, situated between the rivers of Tigris and Euphrates, Harran is located along the transition region between Anatolian and Mesopotamian cultures, which have coalesced and affected each other. In the old inscriptions, Harran used to be named Harranu(m), which can be translated as "caravan path". The latest excavations in Harran and its surrounding region have shown that the first settlement in the close vicinity of Harran dates back to $6000 \mathrm{BC}$ and in its region to $8000-10,000 \mathrm{BC}$ [5]. Systematic agricultural activities have probably started, dating from approximately that period in southeast Anatolia, increasing the possibility that Harran was home to the first settlement dated in this period. The plans of houses, which could be dated to this time, were also circular. Houses of similar circular plans were discovered in excavations of Batman-Hallan Çemi, Diyarbakır-Çayönü, and Urfa-Nevali Çori, which are in the same geographic and climatic zones in southeastern Anatolia. Supposedly, they were the earliest of the circular plan houses. These houses, which were unearthed in the excavations, must have been the prototypes of Harran houses [6].

Another significant feature of the region that makes it suitable for settlement is the difference of altitude from natural water flow. Harran is just $360 \mathrm{~m}$ above the sea 


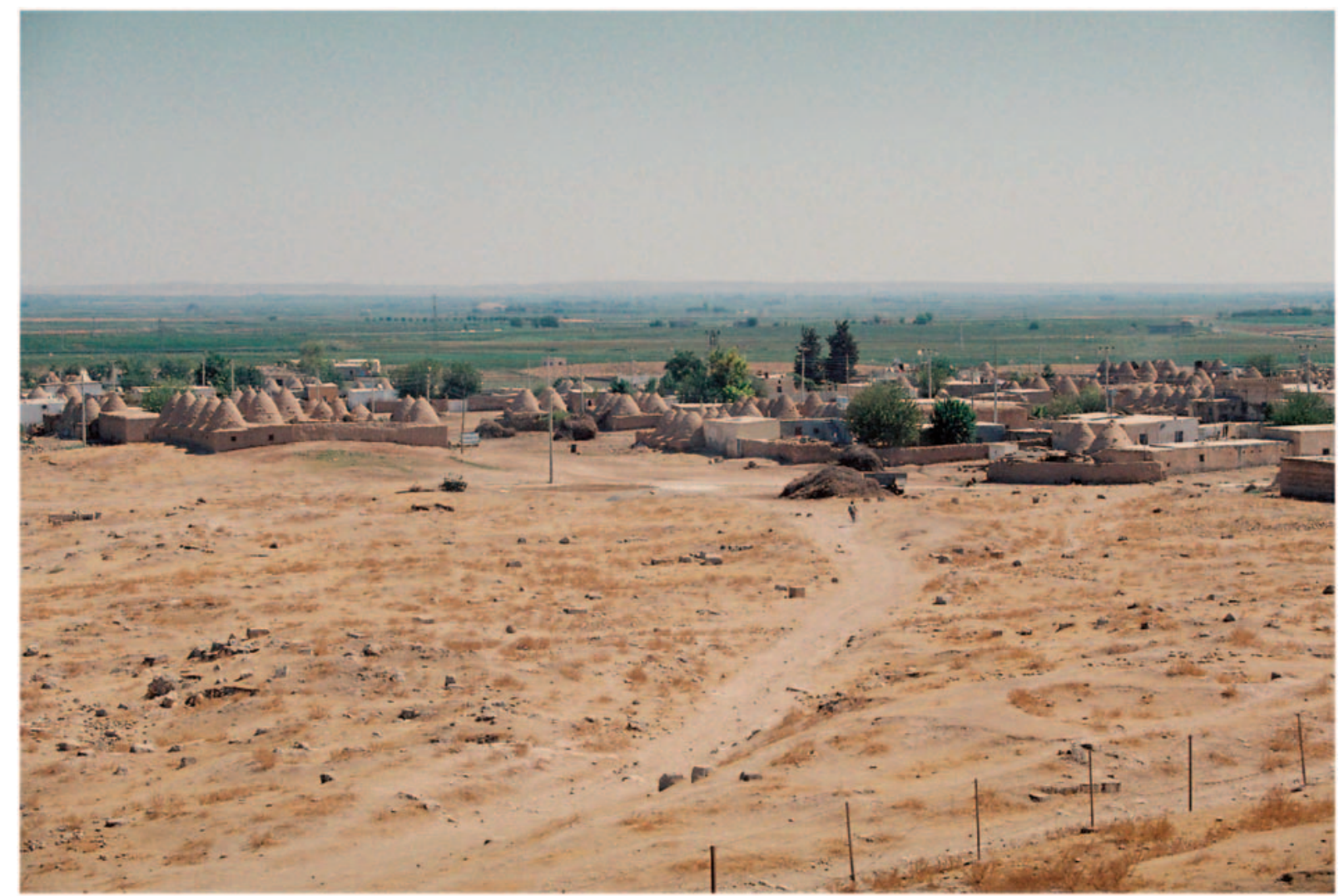

Fig. 1. A part of Harran town with domed houses.

level, which is the lowest among the lowlands in the region. The town of Harran (Figure 1) is surrounded by $5-\mathrm{m}$ high ancient city walls approximately $4.5 \mathrm{~km}$ long, which are in rather good condition. Inside the city wall, there are two wards of domed houses which were built in [7]. The main distinguishing feature of these houses is the dome, which is constructed by means of overlapping bricks. The average wall thickness of Harran houses is around $50-60 \mathrm{~cm}$, and they are built out of stone, brick, and mud for mortar. The dome is usually $20-30 \mathrm{~cm}$ thick with an opening at the top. The opening provides natural ventilation/air circulation inside the house, and the thick-walled structure both thermal insulation and storage. These special features provide relatively good indoor conditions during the year.

Houses covered in domes as a vernacular type can especially be seen in two regions in the world. One of these regions is Apulia, Italy which dates from a relatively late period. In this region, settled between Bari and Taranto, 25,000 domed houses were counted. The other is Harran, having 2760 vernacular domed houses according to a count held in 2002 [8].
Harran lies in a hot-arid climatic region. Since wood is very rare, people who lived there build their houses using brick, stone, and mud, which can be easily found. The construction of the domed houses of Harran could be very rapid and easy. Because of the weak plastering materials, the houses need repairing every 1-3 years. Harran houses are told to be ruined and settled many times during history and their form has evolved over time [9]. Materials like stone and brick for the houses were usually obtained from a quarry in the vicinity and ancient ruins belonging to several cultures in the area. After the 1950s, due to these prohibitions concerning the conservation of historical monuments, materials recycled from these structures were not available, leading to concrete structures being built next to the domed houses. Nowadays, almost nobody lives in the vernacular domed houses in Harran. These buildings have been registered and are under conservation.

Every dome was built approximately on a $3 \times 3 \mathrm{~m}^{2}$ masonry base that is $1.5 \mathrm{~m}$ high using local stones, with a wall thickness of $50-60 \mathrm{~cm}$ plastered from inside and outside. Sometimes, the masonry structure may include brick, supported by a foundation of $1-1.5 \mathrm{~m}$ depth and 


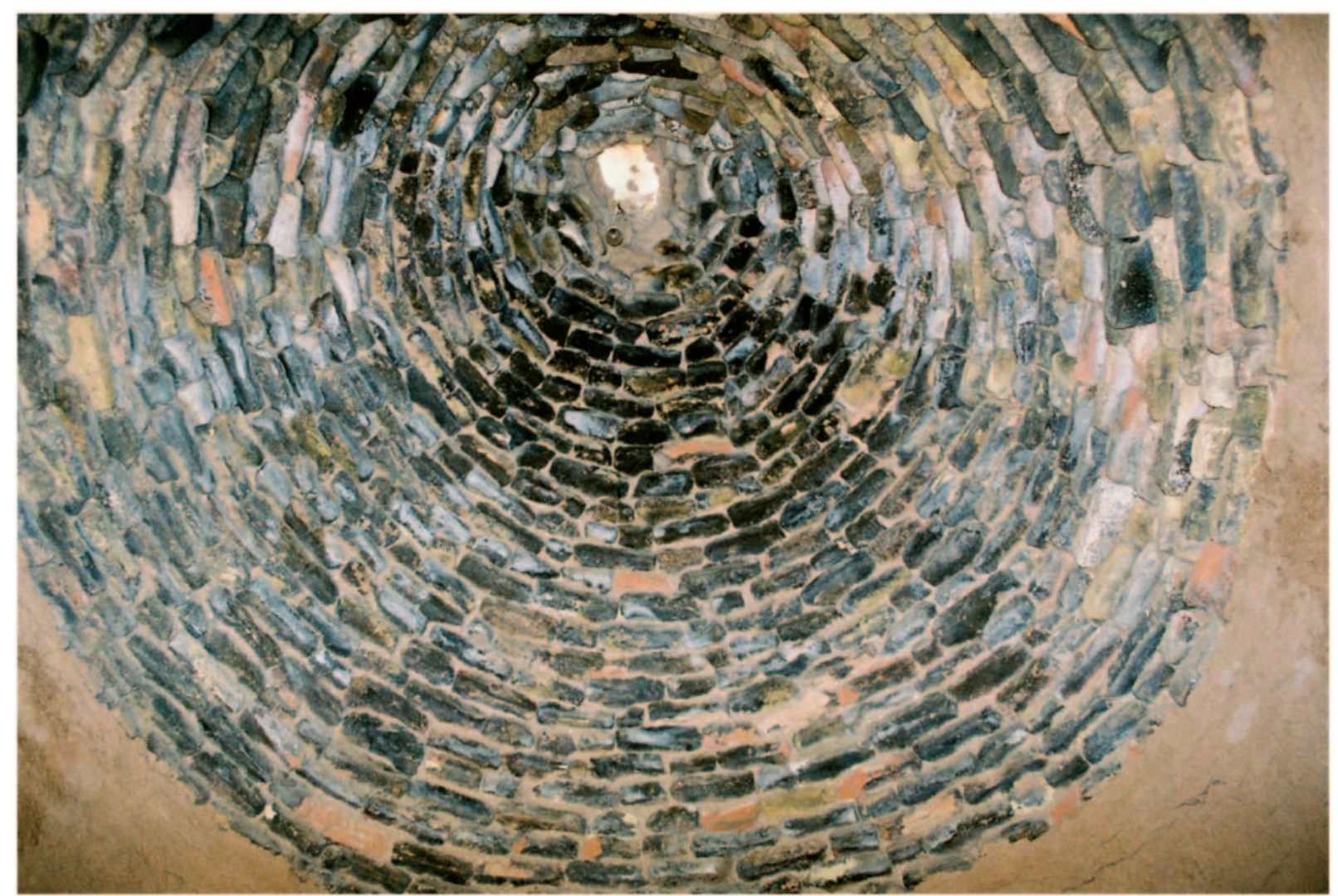

Fig. 2. Internal view of the dome in a Harran house.

filled up using randomly sized rubble. On top of the masonry base, a parabolic cone was erected in overlapping brick recycled from ancient ruins joined by a black sand mortar (Figure 2). Plaster is used only at the bottom part of the cone, approximately to a height of $0.5 \mathrm{~m}$, and the upper part of the cone is left without plaster. The outside is completely plastered. Approximately, 1650 bricks were used for the cone of the domed house. The number of bricks required would depend on the height of the house which could vary between 3.5 and $5 \mathrm{~m}$. A hole of about $20 \mathrm{~cm}$ diameter is left at the top of the dome, where a simple "roof" over the hole is constructed using bricks to provide protection against rain. Usually, the domed units are connected to each other by means of brick arches which link one space to the other in creating the planimetric layout of the house.

\section{Halil Özyavuz Harran House}

A domed house complex named "Halil Özyavuz Harran House" was chosen for the experimental study after carrying out a pre-research in Harran town centre (Figure 3 ). This house complex, approximately 210 years old, has been restored for touristic purposes. The house seemed to be the most suitable option for this research study which also provided for the researchers' accommodation.

The entrance of the house, located at the south side of the complex, opens to a courtyard, and the domed units are placed on the northern and eastern sides of the courtyard, as shown in Figure 4.

The Number 1 unit is the main entrance where an open fire would be burnt in a $1 \times 1 \mathrm{~m}^{2}$ hole of $15 \mathrm{~cm}$ depth in winter when necessary (Figure 4). Numbers 2 and 3 are joined by an arch, which constitute the living room (Figure 5). The oldest married son of the family occupies the two domed sections numbered 4 and 5 . The storage room is the Number 6 unit and is another connection point to the next section. The domed sections numbered 7 and 8 are used by women. This section was used for the research study. Sections 9 and 10 are utilised as kitchen and connected to number 11 with a door. Two domes numbered 11 and 12 are used by the house owners. Smallsized domes numbered 13-16 are utilised as toilets and baths. Two separated domed sections numbered 17 and 18 


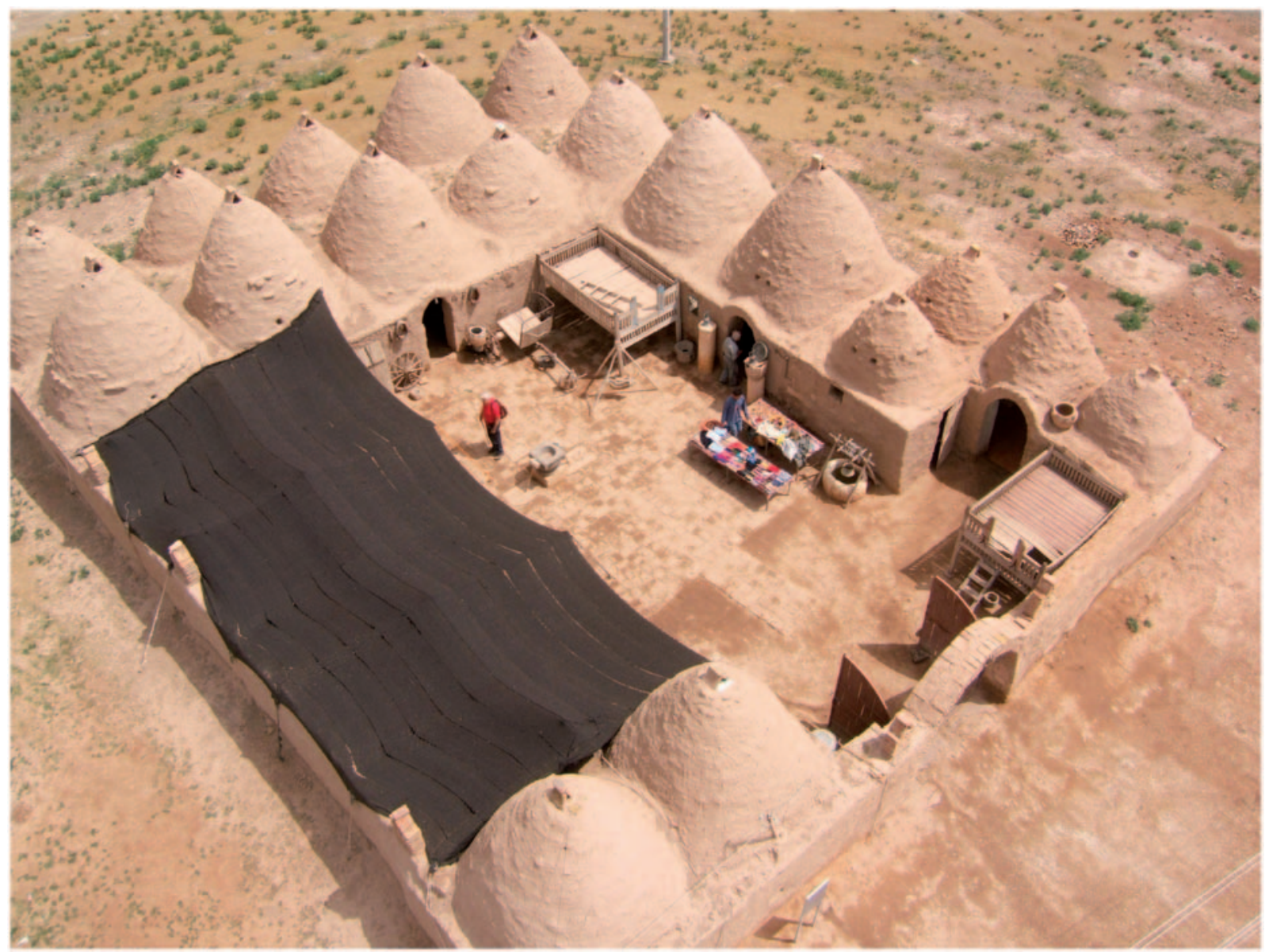

Fig. 3. Halil Özyavuz Harran House.

at the southwest corner of the complex belong to the grandparents of the family, but are now used for visitors.

\section{Experimental Setup}

The domed sections numbered 7 and 8 were the most suitable places to collect the data and were reserved for the research study by the owners. For the thermal analysis, temperatures were recorded on a HIOKI 8421-51 memory hilogger unit using 20 T-type thermocouples (Figure 6). The locations of the thermocouples are shown in Figure 7. Thermocouples numbered 1-6 measured the air temperature inside the two domes at different levels at $2 \mathrm{~m}$ (\#3 and 6), $3.5 \mathrm{~m}$ (\#2 and 5), and $5 \mathrm{~m}$ (\#1 and 4) from the ground. The temperatures of air entering or leaving from the windows and the door were recorded using thermocouples numbered 8-12. Temperatures of different surfaces were measured by thermocouples numbered 13-20. Simultaneously, outside temperature was recorded by thermocouple 7, as indicated in Figure 7. Calibration of the thermocouples was performed using a PT100 probe connected to an HP 3458A multi-meter, both of which were calibrated at the National Metrology Institute of Turkey. The total uncertainty of the calibrated thermocouples and the memory hilogger was estimated as $\pm 1^{\circ} \mathrm{C}$.

Two SATO SK-L200THII $\alpha$ data loggers were also used for recording inside and outside temperatures and relative humidity. One of them was located in the courtyard in the shadow under a tent (Figure 3), and the other recorded the data in room Number 7 at head height level (indicated using a quadrangle with $\mathrm{S}$ in Figure 7). The total uncertainty of the calibrated probes and the data loggers was estimated as $\pm 1{ }^{\circ} \mathrm{C}$ for the temperature measurements and $\pm 3 \%$ for the relative humidity measurements.

Air flow velocity values of airflow through windows and door were monitored in the dome sections numbered 7 and 8 using an AIRFLOW TA-2 anemometer. This measurement was performed during one whole day every half-hour in order to give some rough idea about air movements and energy transfer by air. 


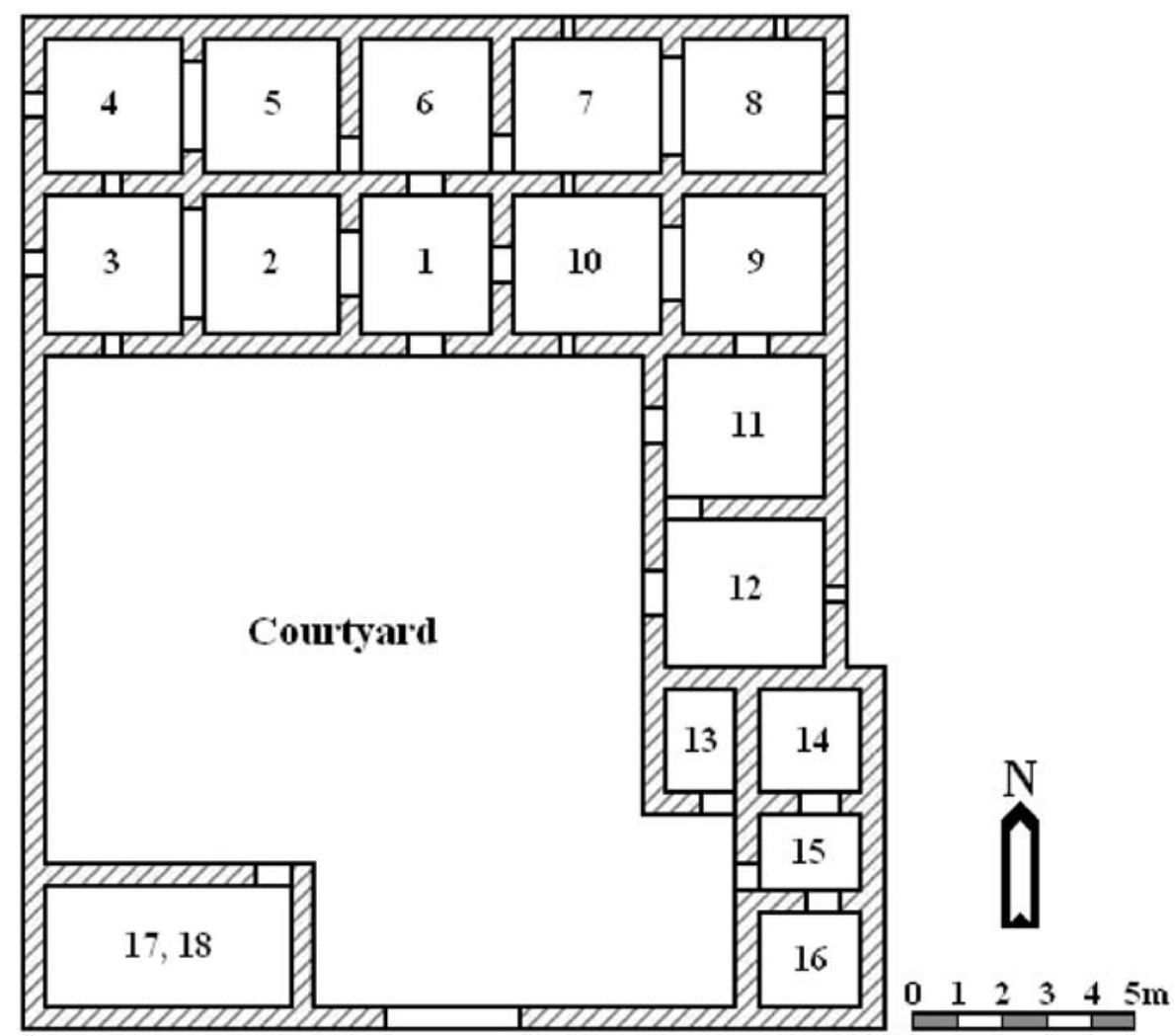

Fig. 4. Plan of "Halil Özyavuz Harran House".

\section{Results and Discussion}

Harran lies in a hot-dry climatic zone with a significant temperature difference between day and night in summer time. To investigate the effect of this extreme condition experimentally, data were collected in July, which has the highest monthly average temperature given as $31.9^{\circ} \mathrm{C}$ (Figure 8 ) by the Turkish State Meteorological Service [10]. In addition to monthly average temperature values between 1975 and 2006, average minimum and maximum temperatures with average number of rainy days are shown in Figure 8. Since the solar gain is an important factor, the experimental study was started at night time on July 15th, 2008 and completed in the early morning of July 19th [11].

Inside and outside temperature and humidity values were recorded at 2-min intervals using SATO data logger from the 15th of July at 20:46 to 19th of July at 05:08 in 2008. The experimental results are presented in Figures 9 and 10, indicating mid-night and noon periods. The great outside temperature difference between night and day measured in shadows in the courtyard are shown in Figure 9. Although the temperature reached $42^{\circ} \mathrm{C}$ in the afternoons and dropped to $22^{\circ} \mathrm{C}$ approximately at night, the inside temperature was not much affected by these fluctuations; it was observed to change only $\pm 3^{\circ} \mathrm{C}$ and stayed around $30^{\circ} \mathrm{C}$ due to the thermal behaviour of the structure. Time difference between the highest and lowest temperature values of the inside and outside is shown in Figure 9. Inside temperature reached its highest value approximately $2 \mathrm{~h}$ after outside temperature started decreasing. The phase difference was only $1 \mathrm{~h}$ for the lowest temperature degrees between outside and inside.

Similar behaviour is also shown for the relative humidity, as illustrated in Figure 10. Although the humidity of the outside fluctuated with a great difference, the inside humidity was within the relatively comfortable condition, which was between $30 \%$ and $50 \%$ during the monitoring periods. Outside relative humidity reached its top value just before daybreak and decreased in the afternoon hours. Figures 9 and 10 illustrate a contrasting behaviour of temperature and relative humidity variations during a time period.

As the author stayed at the "Halil Özyavuz Harran House" during the monitoring period, inside and outside conditions were also observed personally. While it was not 


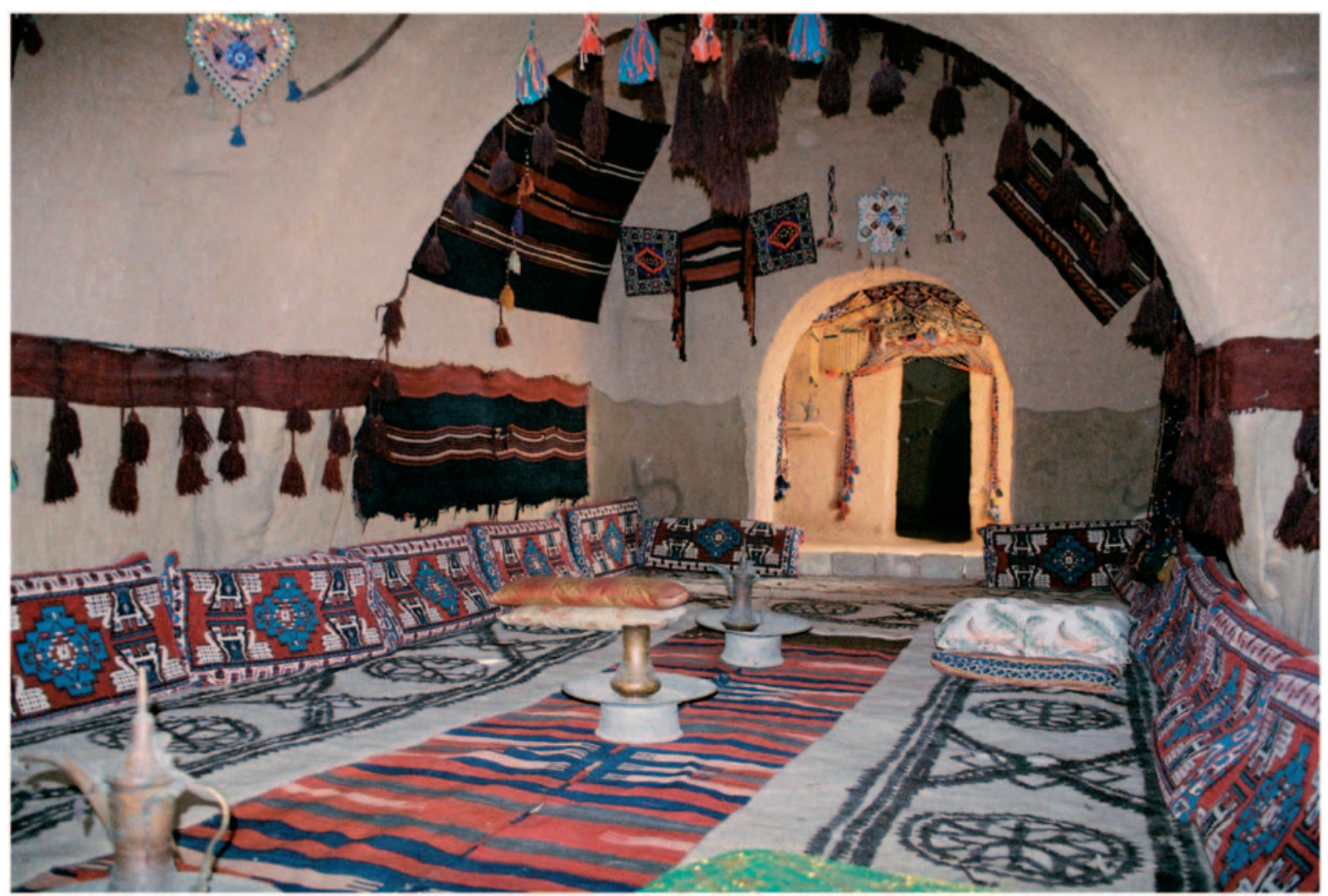

Fig. 5. Inside view of the domed houses numbered 3 and 2, respectively.

possible to stay under the sun, which was very hot during daytime; the indoor conditions were comfortable in the house. On the other hand, although sleeping outside is common in this region, the night time temperatures inside the house was not so high, as seen in Figure 9. Nevertheless, people prefer to sleep outside on a wide and high bed called "throne" with thick quilts because of the respectively cold weather (two of them can be seen in the courtyard in Figure 3), as the first rays of the sun are very effective in waking them up early in the morning.

Exit air temperatures from the dome, as measured at 8, and $2 \mathrm{~m}$ high level using two thermocouples numbered 1 and 3, respectively, are shown in Figure 11. In the morning hours (06:00 am to 12:00), there was no significant difference between these two temperature values due to the thermal equilibrium between outside and inside temperatures (Figure 9), and no windy conditions outside were noticed. The two temperature values fluctuated during afternoon hours under an unstable wind velocity and chimney effect conditions, when significant temperature difference could be detected. After sunset, temperature values decreased gradually, giving relatively stable conditions during the night hours. Approximately, $1.5^{\circ} \mathrm{C}$ temperature difference occurred inside the two levels of the dome and the air flow was mainly created by the buoyancy forces that evolve from density gradients induced by this temperature difference inside the dome. Similar behaviour was observed for the other dome numbered 7.

Inside thermal conditions were investigated using transient energy analysis of the control volume of the domed houses numbered 7 and 8 . Kinetic and potential energy changes associated with the fluid flows and the control volume inside the domed sections 7 and 8 were neglected. As such, the mass rate and energy rate balance relations for this transient uniform flow process are evaluated by Equations (1) and (2), respectively, for every half-an-hour during the day. All terms in Equation (1) are expressed in $\mathrm{kg} \cdot \mathrm{s}^{-1}$ and $\dot{m}$ the mass flow rate.

$$
\sum_{\text {in }} \dot{m}-\sum_{\text {out }} \dot{m}=\left(\frac{\Delta m}{\Delta t}\right)_{c v}
$$




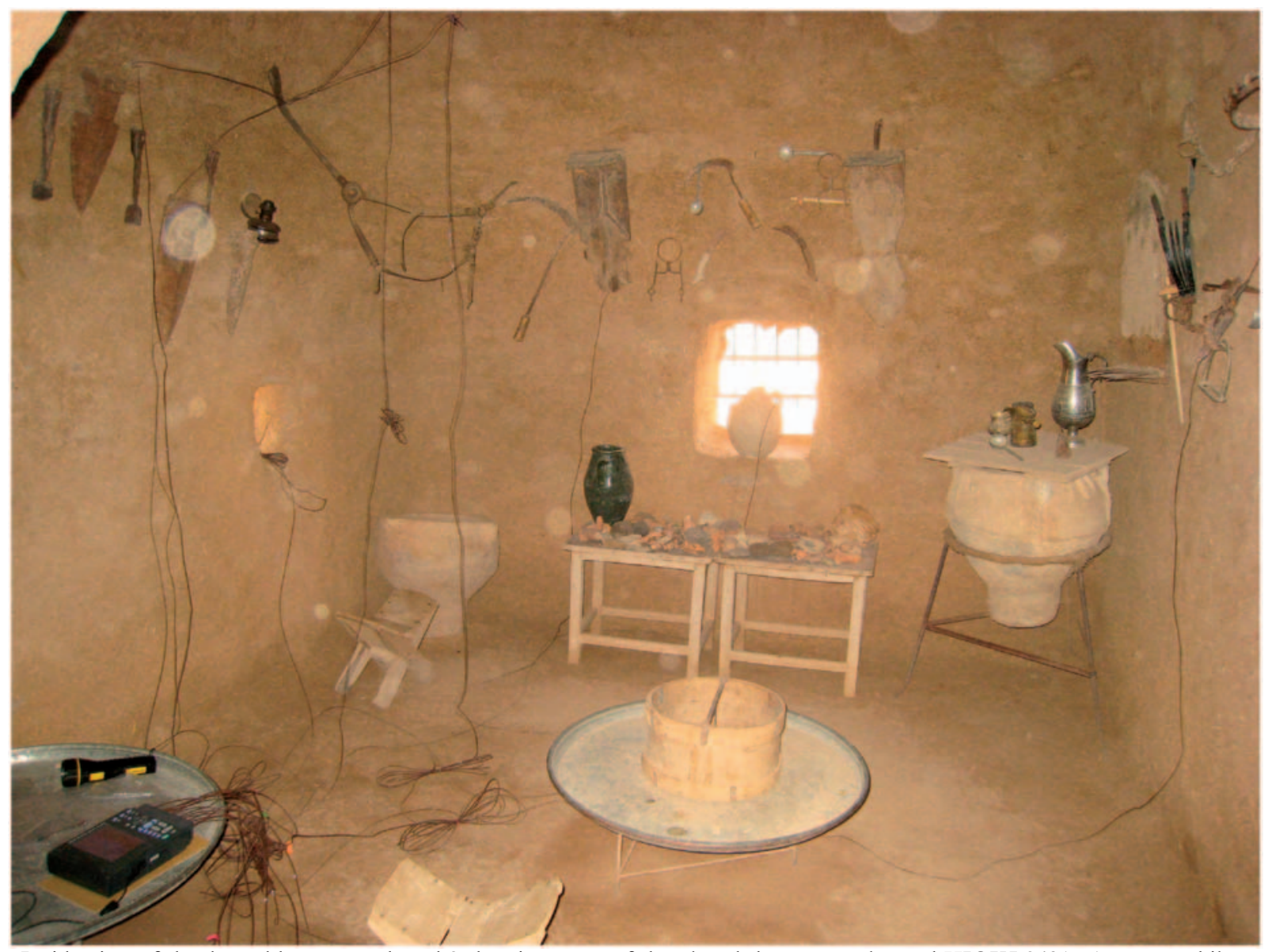

Fig. 6. Inside view of the domed house numbered 8 showing some of the placed thermocouples and HIOKI $8421-51$ memory hilogger unit.

where $\Delta m / \Delta t$ is the time rate of mass within the control volume $(c v)$. The mass of the air inside the control volume was assumed to be steady during the experiment. But, air mass flow rates of the inlet and outlet sections of the houses were determined and changed for every halfan-hour. There were three windows opening to the outside in sections 7 and 8 . Two of them (cross-section areas were $0.25 \times 0.30 \mathrm{~m}^{2}$ for $\# 7$, and $0.20 \times 0.20 \mathrm{~m}^{2}$ for $\# 8$ ) faced north, and the other one (cross-section area was $0.50 \times 0.50 \mathrm{~m}^{2}$ ) was situated on the east side of section 8 . A door connecting sections 7 and 6 had a dimension of $0.80 \times 1.50 \mathrm{~m}^{2}$. There was another small window $\left(0.20 \times 0.40 \mathrm{~m}^{2}\right)$ which opened to section 10 , in room 7 . Every dome had a small opening with an approximate diameter of $0.20 \mathrm{~m}$ at the top. They were left open all day, so that air could exit and/or enter the sections. Air velocity values and directions for the cross-sections were determined during the day and the inlet and/or outlet mass flow rates calculated for every time step. For the calculations, energy equation was written assuming air as an ideal gas in
Equation (2), and all terms are expressed in Watts. The terms $\dot{Q}$ and $\dot{W}$ denote the energy transfer rate by heat and work, respectively, across the control volume boundary.

$$
\dot{Q}-\dot{W}=\sum_{o u t} \dot{m} c_{p} T-\sum_{\text {in }} \dot{m} c_{p} T+\left[\frac{m c_{v}\left(T_{i+1}-T_{i}\right)}{\Delta t}\right]_{c v}
$$

where $T$ is the temperature $\left({ }^{\circ} \mathrm{C}\right)$. The subscripts $i$ and $i+1$ denote the time step which is half-an-hour increment. Air temperature was also recorded for every control surface wherever air flow existed using thermocouples numbered 1,4 , and $8-12$. So, the rate of energy transport by air mass was calculated and given graphically for $24 \mathrm{~h}$ between the noons of 16th and 17th of July in 2008, as shown in Figure 12. This fluctuation was indicated by "enthalpy" in Figure 12, and a third-degree polynomial line was matched to the data. Specific heat values of air did not vary for this working condition, and were assumed as $c_{v}=0.719 \mathrm{~kJ} \cdot \mathrm{kg}^{-1} \mathrm{~K}^{-1}, c_{p}=1.007 \mathrm{~kJ} \cdot \mathrm{kg}^{-1} \mathrm{~K}^{-1}$, but variations of air density by temperature were determined for the calculation of the mass flow rate. Thermophysical 


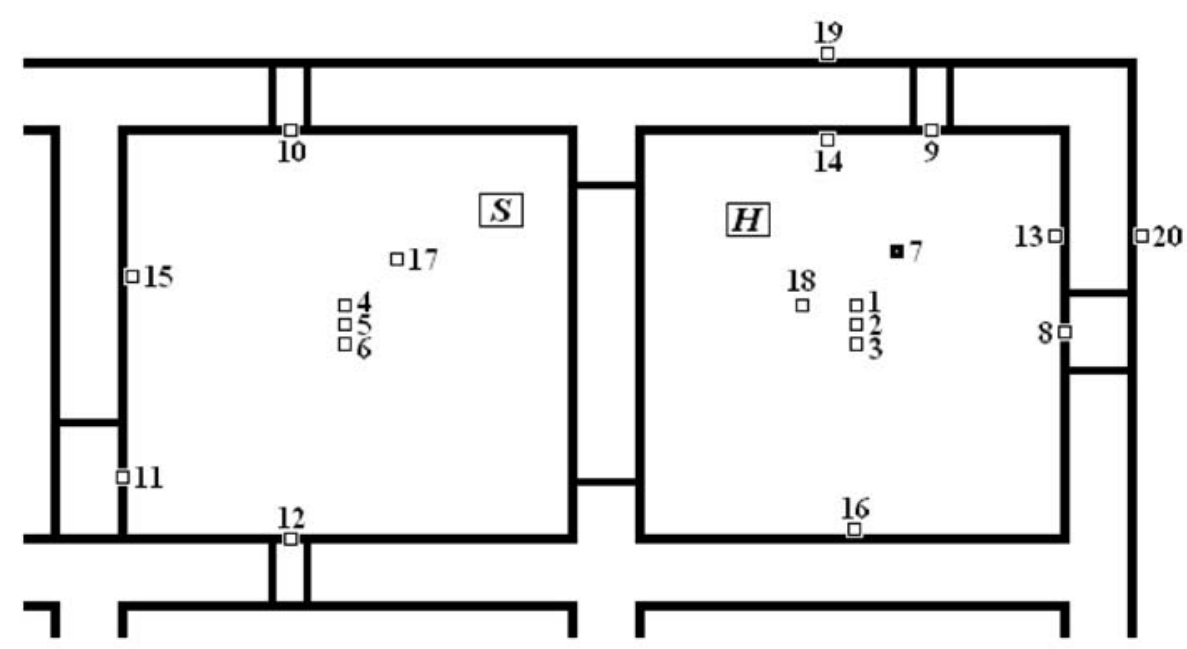

Fig. 7. Location of the thermocouples with the HIOKI 8421-51 memory hilogger (indicated as H), and SATO SK-L200THII $\alpha$ data logger (indicated as $\mathrm{S}$ ).

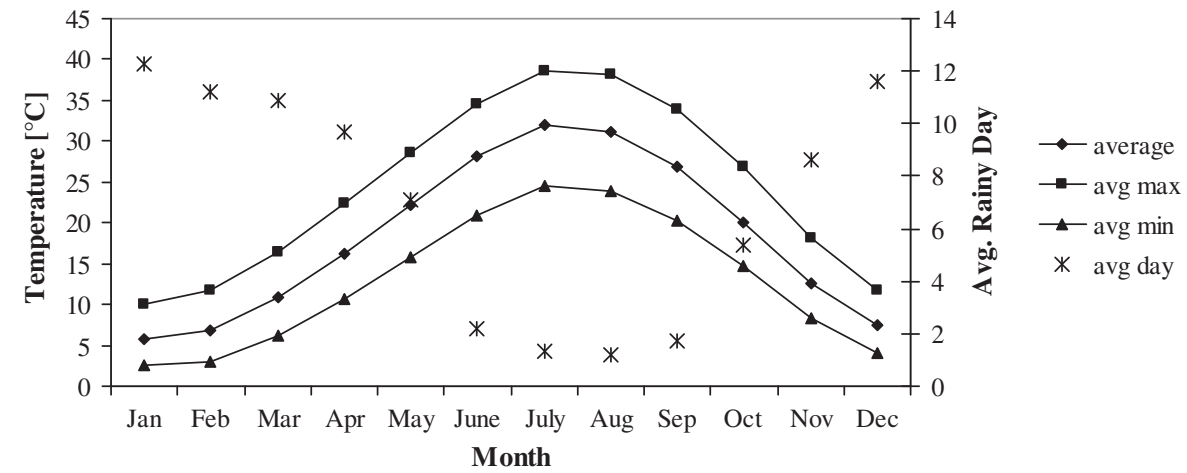

Fig. 8. Average temperatures and number of average rainy day variations [10].

properties of air were taken from reference [12]. On the other hand, heat transfer rates along walls between inside surfaces to air were determined using the thermocouples numbered 2, 3, 5, 6 (for air) and 13-18 (for surfaces). Convection heat transfer coefficient was assumed to be $5 \mathrm{~W} \cdot \mathrm{m}^{-2} \mathrm{~K}^{-1}$ for inside surfaces, whereas $10 \mathrm{~W} \cdot \mathrm{m}^{-2} \mathrm{~K}^{-1}$ was used for the outside surface of the domes. Results are drawn for every half-an-hour, and indicated by "heat" in Figure 12. Again, a third-degree polynomial was matched with these data.Electrical power gain from the data loggers and the computer and the rate of heat gain from people who visited the sections were neglected because they were small quantities. Internal energy of air inside the sections varied little between -20 and $30 \mathrm{~W}$ approximately during the day. These values completed the energy balance in Equation (2), and the two polynomial lines in Figure 12 had dampened each other with these results. These values did not match at every time step since the inside condition was sensitive in calculating the rate of energy. Air flow was unstable and the calculation results were quite rough. However, these polynomial lines in Figure 12 give an idea, mainly about the heat transfer mechanism of the inside conditions.

Surface temperature values at the outside and inside were recorded for the north and east walls, respectively, of the domed sections numbered 8, as seen in Figure 13. Inside surface temperature values measured using thermocouples numbered 13 and 14 were almost stable during the monitoring. On the other hand, outside surface temperatures reached high values due to the sun. Especially, the exterior surface temperature of the east wall increased sharply under the influence of the sun and reached $54^{\circ} \mathrm{C}$ before noon. After that, the temperature decreased gradually since the surface was not exposed to direct sunlight. Also, the north side of the wall was not directly influenced by the sun. Because of that, surface temperature 


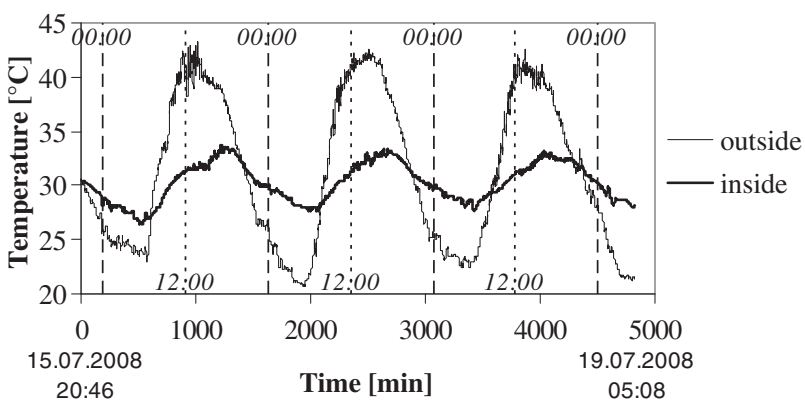

Fig. 9. Temperature variations inside and outside of the domed house.

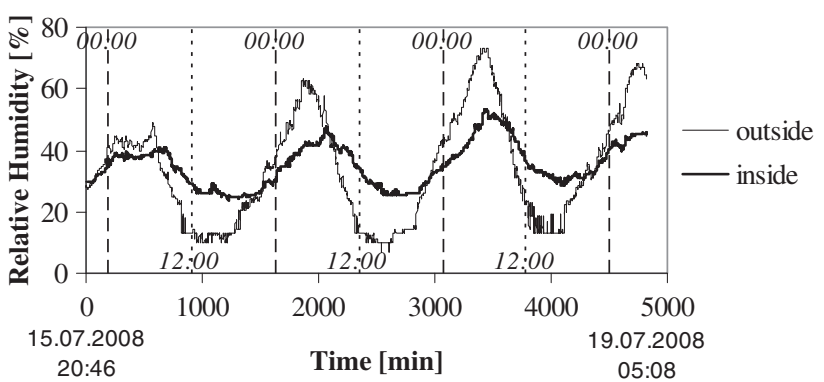

Fig. 10. Relative humidity variations inside and outside of the domed house.

first increased gradually and decreased with the same slope and did not reach high values like the east side of the wall. However, these fluctuations did not affect the inside surface temperatures, which changed only by $\pm 1^{\circ} \mathrm{C}$. The thick structure and thermophysical properties of the wall yielded these results.

For investigating the thermal behaviour of the wall under extreme conditions, one-dimensional (1D) transient heat conduction problem was solved using boundary conditions determined by the field monitored data. Thermophysical properties of the wall built using local stones, bricks, and black and red sand were measured. Densities of the materials were obtained using a balance instrument called Precisa XB220A. Thermal conductivities of the samples were also measured by hot-wire method using the Shotherm QTM device. Specific heat values were determined using the instrument DSC Q10 V9.4. Average values of the thermophysical properties at $30^{\circ} \mathrm{C}$ were used in the analysis, as given in Table 1.

Temperature distributions within the wall were obtained from the numerical solution of a $1 \mathrm{D}$, timedependent heat conduction equation. Boundary conditions were assigned to complete the model. They were defined by the transient monitored results determined

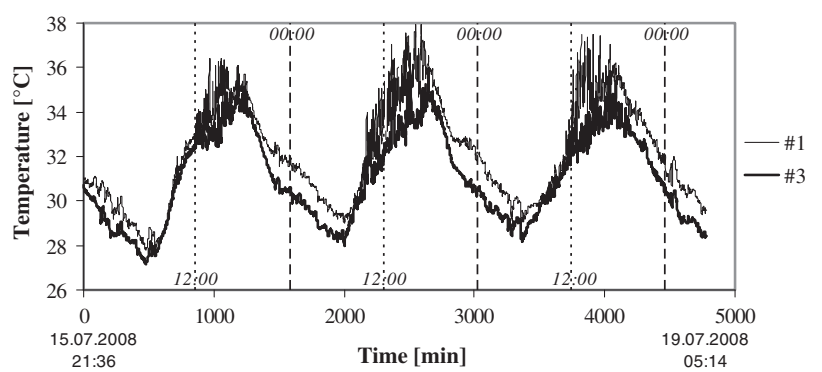

Fig. 11. Temperature variations at two different levels of the dome.

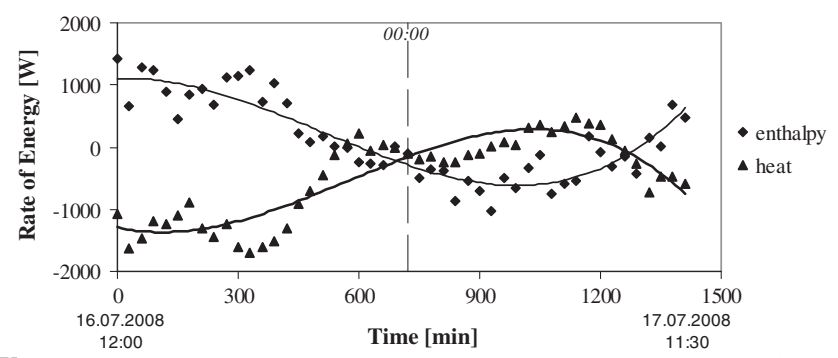

Fig. 12. Rate of energy transport by inlet/outlet air, and heat transfer from/to the inside sections from the surfaces of the walls.

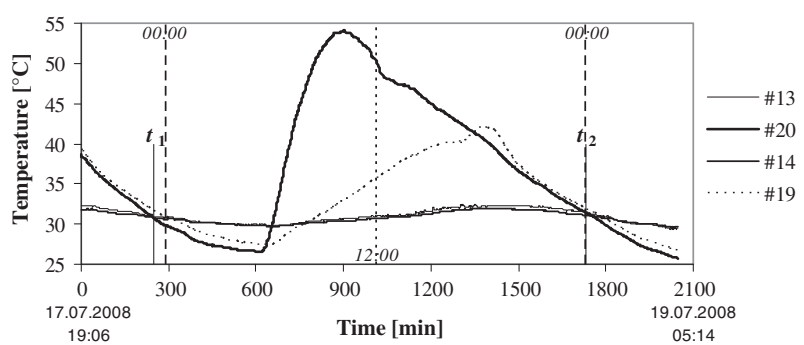

Fig. 13. Inside and outside surface temperature variations.

from the inside and outside surface temperatures. 1D, time-dependent heat conduction equation was expressed by the finite difference method, and a computer program was written using the implicit method. The results for different time steps indicated by $0 \mathrm{~h}$ (initial condition) to $24 \mathrm{~h}$ (24th hour) are shown in Figure 14. Since the wall thickness of the structure was not the same at every section and varied within $50-60 \mathrm{~cm}$, an average value of $55 \mathrm{~cm}$ was considered. Wall material was not homogenous. Although generally local stone was used for erecting the walls, bricks and sand were also utilised as complementary materials. For this reason, weighted average values of thermophysical properties, namely thermal diffusivity, $\alpha=4.14 \mathrm{E}-$ $07 \mathrm{~m}^{2} \cdot \mathrm{s}^{-1}$ and thermal conductivity, $k=0.975 \mathrm{~W} \cdot \mathrm{m}^{-1} \mathrm{~K}^{-1}$ were determined by the computer program. 
Table 1. Thermophysical properties of the building elements used in Harran house

\begin{tabular}{lccc}
\hline Materials & Density, $\rho\left[\mathrm{kg} \cdot \mathrm{m}^{-3}\right]$ & Specific heat, $c\left[\mathrm{~J} \cdot \mathrm{kg}^{-1} \mathrm{~K}^{-1}\right]$ & Thermal conductivity, $k\left[\mathrm{~W} \cdot \mathrm{m}^{-1} \mathrm{~K}^{-1}\right]$ \\
\hline Stone & 1922 & 1224.8 & 1.144 \\
Brick & 2162.5 & 972.9 & 0.372 \\
Black sand & 2039 & 1467.2 & 0.199 \\
Red sand & 2089 & 1425.2 & 0.253 \\
\hline
\end{tabular}

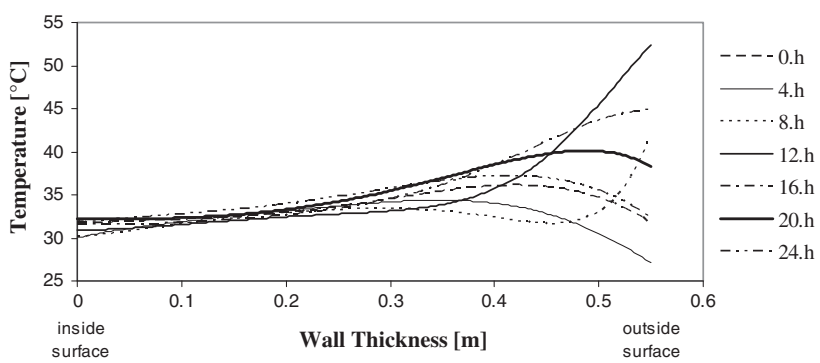

Fig. 14. Temperature distributions in the east wall of section 8 for different time steps.

The computer program was run approximately for 1 day starting from the equality of the inside and outside temperatures, as indicated by $t_{1}$ in Figure 13. Although the initial condition was defined as uniform inside the wall as a first assumption, temperature distribution of the last time step (indicated as $t_{2}$ when inside and outside surface temperatures were the same, as shown in Figure 13) was used as input for the initial condition during the second run of the program. This variation is shown as $0 \mathrm{~h}$ in Figure 14. Other time steps can also be followed in the same figure. For $12 \mathrm{~h}$, although the outside surface temperature reached over $50^{\circ} \mathrm{C}$, more than half the thickness of the wall temperature was not affected by this. On the other hand, the inside surface temperature was somewhat higher at 16 and $20 \mathrm{~h}$.

Weighted average temperature $\left(T_{\text {avg }}\right)$ and energy storage $\left(Q_{s t}\right)$ per $\mathrm{m}^{3}$ of section 8 's east wall is shown in Figure 15 approximately for a day starting from 17 th of July at 23:14 (it is also indicated as $t_{1}$ in Figure 13). Weighted average temperature and energy storage variations by time showed a harmonic behaviour, as expected. At the end of the 1-day period, because the weighted average temperature did not reach the initial condition, energy storage could not complete the period, since 0 and $24 \mathrm{~h}$ temperature distributions in the wall do not match exactly, as seen in Figure 14. Because of the huge thermal mass of the wall, weighted average temperature varied approximately $\pm 2^{\circ} \mathrm{C}$ around $33.7^{\circ} \mathrm{C}$ mean value.

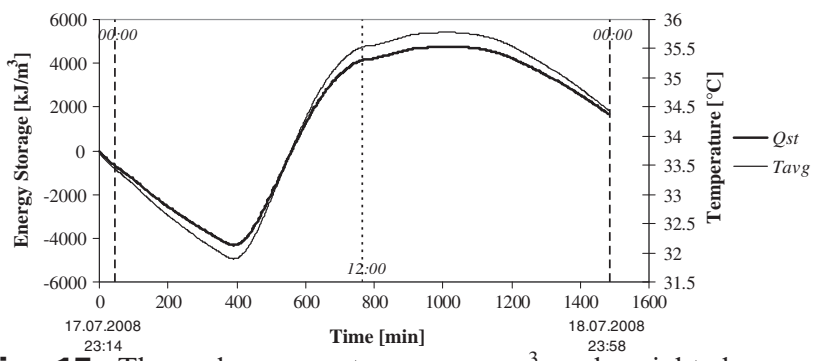

Fig. 15. Thermal energy storage per $\mathrm{m}^{3}$ and weighted average temperature of the east wall of section 8 .

\section{Conclusion}

In this study, a thermal analysis has been carried out for a domed Harran House complex. The experimental results show that interior condition of the building complex was quite comfortable even under extreme outside conditions during summer. The main factors that influenced the level of comfort are the heat storage capacity of the building materials, their construction in this specific case and the natural ventilation within the domes. The great difference in outside temperatures between night and day helps the indoor thermal comfort. Relatively low temperature during the night and the clear summer sky during the testing period also factored in the cooling obtained by heat radiating into the atmosphere, preparing the houses for the hot summer day. Heat gain and loss via the storage capacity of building materials and via the ventilation within the domes have an approximately equal value, which almost cancel each other out in terms of total heat gain within the 24-h cycle. Temperature distributions within the wall obtained from the numerical transient 1D heat conduction solution indicate how important the thickness of the wall and the thermophysical properties of the wall materials are. Thinner walls made of lighter materials would clearly engender insufficient indoor thermal comfort in summer time. 
The domed vernacular houses of Harran in the hot arid climate of southeastern Anatolia are noteworthy examples regarding energy-efficient design for a sustainable future. Their unique architectural features provide acceptable thermal comfort inside the houses without the need for energy consumed by air conditioning and other remedies. What makes Harran houses even more significant as a vernacular type is that they were built using recycled materials obtained locally and erected rapidly in a way which reduced energy consumption levels in the construction phase.

\section{Acknowledgements}

This study was supported by Dokuz Eylül University, Department of Scientific Projects, under the grant number 2008 KB FEN 7. The author thanks Dr Erdem Erten from the Department of Architecture, Izmir Institute of Technology, Turkey for his valuable comments.

\section{References}

1 Y1lmaz Z: Evaluation of energy efficient design strategies for different climatic zones: Comparison of thermal performance of buildings in temperature-humid and hot-dry climate: Energy Build 2007;39: 306-316.

2 Cardinale N, Micucci M, Ruggiero F: Analysis of energy saving using natural ventilation in a traditional Italian building: Energy Build 2003;35:153-159.

3 Ealiwa MA, Taki AH, Howarth AT, Seden MR: An investigation into thermal comfort in the summer season of Ghadames, Libya: Build Environ 2001;36:231-237.
4 Harputligil GU, Çetintürk N: Evaluation of thermal comfort conditions of traditional Turkish houses: Hacı Hüseyinler house in Safranbolu: J Fac Eng Arch Gazi Univ 2005;20(1):77-84 (in Turkish).

5 Yardimcı N: The Gate Opened Through Mesopotamia, Harran. Istanbul, Ege Yayınları, 2007.

6 Sağlamtimur H: Personal communication. 9th October 2008

7 Yardımcı N: Surface Research of Harran Lowlands 1. İstanbul, Arkeoloji ve Sanat Yayınları, 2004.

8 Başgelen N: Birecik-Suruç. İstanbul, Türkiye Bilimler Akademisi, 2003 (in Turkish).
9 Özdeniz MB, Bekleyen A, Gönül IA, Gönül H, Sarıgül $H$, İlter $T$, Dalkılıç N, Yildirım M: Vernacular domed houses of Harran, Turkey: Habitat Int 1998;22(4): $477-485$.

10 Turkish State Meteorological Service. Available at: http://www.dmi.gov.tr/index. aspx (accessed April 22, 2010).

11 Duffie JA, Beckman WA: Solar Engineering of Thermal Processes. New York, John Wiley \& Sons, 1991.

12 Çengel YA, Cimbala JM: Fluid Mechanics, Fundamentals and Applications. New York, McGraw-Hill, 2006. 